Gut and Liver, Vol. 11, No. 6, November 2017, pp. 743-744

\title{
Can We Trust Safety of Tenofovir Disoproxil in Patients with Decompensated Cirrhosis?
}

\author{
Hyunwoo Oh and Dae Won Jun \\ Department of Internal Medicine, Hanyang University College of Medicine, Seoul, Korea
}

See "Effects of Entecavir and Tenofovir on Renal Function in Patients with Hepatitis B Virus-Related Compensated and Decompensated Cirrhosis" by Jihye Park, et al. on page 828, Vol. 11. No. 6, 2017

Recently, Park et al., ${ }^{1}$ reported renal safety of tenofovir (TDF) in decompensated cirrhosis patients. Currently, most guidelines recommend the use of nucleos(t)ide analogues (NAs) for chronic hepatitis $\mathrm{B}(\mathrm{CHB})$ infection as a treatment of choice. ${ }^{2}$ Among the treatments, TDF and entecavir (ETV) are the two proven effective drugs for CHB patients. However, all NAs have potential risk for mitochondrial dysfunction, and TDF is particularly associated with proximal renal tubule damage. There are several reports regarding risk of TDF associated renal toxicity and osteoporosis. Although several studies emphasized the possibility that TDF might impair renal function and bone density; it is not clear whether this decline in renal function and bone density has clinical meaning. Therefore, we reviewed several studies on the renal safety of TDF and ETV.

In the current issue, Park et al. ${ }^{1}$ conducted a single center retrospective cohort study of $\mathrm{CHB}$ patients with compensated and decompensated cirrhosis. At 96 weeks of observation, changes in estimated glomerular fraction rate (eGFR) and serum creatinine in TDF users were not statistically different with that of ETV users. There was no significant difference in number of patients showing more than $0.2 \mathrm{mg} / \mathrm{dL}$ increase in serum creatinine or 20\% decrease in eGFR at the end points of the study. Multivariate analysis showed that baseline eGFR, diabetes, and diuretics use was associated with eGFR reduction of more than $20 \%$, and the use of antiviral agents was not an independent risk factor for renal insufficiency incidence. It is still debatable whether TDF compared to ETV could decrease eGFR, which is both clinically and statistically significant. Lok et al., ${ }^{3} 11$ studies meta-analysis showed no significant difference in renal safety profiles of TDF and ETV. However, Han et al., ${ }^{4}$ recently reviewed 12 studies, and showed that the incidence of creatinine increase and eGFR decrease was higher in TDF group compare to ETV group (relative risk, $1.601 ; 95 \%$ confidence interval, 1.035 to 2.478; $\mathrm{p}=0.0034 ; \mathrm{I}^{2}=0.0 \%$ ). Recent European Association for Study of the Liver (EASL) guidelines recommend the use of ETV rather than TDF in patients who are over 60 years, with bone disease or with decreased renal function (eGFR $<60 \mathrm{~mL} / \mathrm{min}$, albuminuria, on hemodialysis). ${ }^{2}$

Park et al.'s paper is very interesting in several respects. First, all the study participants were cirrhotic. The studies focusing only on cirrhotic patients are rare. Although, about 12 studies comparing NAs safety have been published; however, most studies focused on hepatitis naïve patients, and the study sample did not had cirrhotic patients. Moreover, most studies did not even mention the exact proportion of cirrhosis patients, and sometimes decompensated cirrhosis patients were also excluded. Second, Park et al. provided detail information on changes of creatinine/eGFR over 2 years. Most studies simply suggested the prevalence of acute kidney injury (AKI) using various AKI criteria during different observation periods. However, the precise serum creatinine and eGFR changes were not mentioned. According to Han et al., systematic review, only two of 12 articles (including randomized controlled trial, cohort) mentioned quantitative numerical values regarding renal safety. In this paper, multivariate analysis showed that diuretics use, diabetes, and low eGFR are the risk factors for renal dysfunction which is not different from previous studies. Shin et al. ${ }^{5}$ analyzed 4,178 CHB patients and found that age, hypertension, diabetes, liver or kidney transplantation, underlying chronic kidney disease (CKD), and diuretics were the risk factors for renal insufficiency during NAs use. Importantly, the prevalence of diabetes and diuretics prescription also increases in decompensated cirrhosis. Al-

\footnotetext{
Correspondence to: Dae Won Jun

Department of Internal Medicine, Hanyang University College of Medicine, 222-1 Wangsimni-ro, Seongdong-gu, Seoul 04763, Korea

Tel: +82-2-2290-8338, Fax: +82-2-972-0068, E-mail: noshin@hanyang.ac.kr

pISSN 1976-2283 eISSN 2005-1212 https://doi.org/10.5009/gnl17401

(a) This is an Open Access article distributed under the terms of the Creative Commons Attribution Non-Commercial License (http://creativecommons.org/licenses/by-nc/4.0) which permits unrestricted non-commercial use, distribution, and reproduction in any medium, provided the original work is properly cited.
} 
though, several comorbidities can accompany along the course of cirrhosis; however, some studies excluded patients taking medications (diuretics, etc.) that might exacerbate renal function. Moreover, due to diverse research designs, it is difficult to compare the previous studies. The treatment naïve percentage, treatment period, and inclusion criteria were different. Moreover, definition of AKI (eGFR decreased by more than 20\%, eGFR $<60 \mathrm{~mL} / \mathrm{min}$, serum creatinine increased by 0.3 or $0.5 \mathrm{mg} / \mathrm{dL}$ ) and methods of estimating renal function (Cockcroft-Gault equation, modification of diet in renal disease, CKD epidemiology collaboration) were also different in various studies (Table 1). ${ }^{6-9}$

Although, Park's study is the largest study evaluating renal safety of ETV and TDF in cirrhotic patients; however, additional high-quality longitudinal studies which could evaluate renal safety in high-risk groups are still needed.

\section{CONFLICTS OF INTEREST}

No potential conflict of interest relevant to this article was reported.

\section{REFERENCES}

1. Park J, Jung KS, Lee HW, et al. Effects of entecavir and tenofovir on renal function in patients with hepatitis B virus-related compensated and decompensated cirrhosis. Gut Liver 2017;11:828-834.

2. European Association for the Study of the Liver. EASL 2017 clinical practice guidelines on the management of hepatitis B virus infection. J Hepatol 2017;67:370-398.

3. Lok AS, McMahon BJ, Brown RS Jr, et al. Antiviral therapy for chronic hepatitis B viral infection in adults: a systematic review and meta-analysis. Hepatology 2016;63:284-306.

4. Han Y, Zeng A, Liao H, Liu Y, Chen Y, Ding H. The efficacy and safety comparison between tenofovir and entecavir in treatment of chronic hepatitis B and HBV related cirrhosis: a systematic review and meta-analysis. Int Immunopharmacol 2017;42:168-175.

5. Shin JH, Kwon HJ, Jang HR, et al. Risk factors for renal functional decline in chronic hepatitis B patients receiving oral antiviral agents. Medicine (Baltimore) 2016;95:e2400.

6. Liaw YF, Sheen IS, Lee CM, et al. Tenofovir disoproxil fumarate (TDF), emtricitabine/TDF, and entecavir in patients with decompensated chronic hepatitis B liver disease. Hepatology 2011;53:62-72.

7. Hung $\mathrm{CH}, \mathrm{Hu} \mathrm{TH}, \mathrm{Lu} \mathrm{SN}$, et al. Tenofovir versus entecavir in treatment of chronic hepatitis B virus with severe acute exacerbation. Antimicrob Agents Chemother 2015;59:3168-3173.

8. Cholongitas E, Papatheodoridis GV, Goulis J, et al. The impact of newer nucleos(t)ide analogues on patients with hepatitis B decompensated cirrhosis. Ann Gastroenterol 2015;28:109-117.

9. López Centeno B, Collado Borrell R, Pérez Encinas M, Gutiérrez Garcia ML, Sanmartin Fenollera P. Comparison of the effectiveness and renal safety of tenofovir versus entecavir in patients with chronic hepatitis B. Farm Hosp 2016;40:279-286. 